\title{
ENSINO LIBERTÁRIO E ESCOLANOVISMO: CONFLUÊNCIAS E DESENCONTROS DE SABERES
}

\author{
Gesualda dos Santos Rasia
}

RESUMO: Le but de ce texte c'est, sous la perpesctive de l'Analyse du Discours ligne française, reflechir sur le concept de paraphrase discursive par le biais des diferents domaines de mémoire qui sont actionnés par les constructions paraphrastiques et par la multiplicité de sens que peut à partir de là deriver. Pour ce faire nous dirigeons notre regard sur deux lieux discursifs que versent autour des questions sur l'enseigment pendant la $2^{a}$ République au Brésil:celui de la Formation Discursive "Escolanovista" (FDE), dont les ennoncés choisis comme corpus d'analyse ont été extraits du Manifesto dos Pioneiros da Educação (1932), et celui de la Formation Discursive "Libertária" (FDL), qui a eu son projet scolaire, réglé par les mêmes proncipes de l'Education libertratrice préconisée en Europe, répandu au Brésil par la presse alternative.

PALAVRAS-CHAVE: educação, escolanovismo, escolas libertárias, paráfrase, determinação, memória, sentidos.

\section{PARA INÍCIO DE CONVERSA}

O espaço da educação oficial historicamente tem se configurado

Gesualda dos Santos Rasia é professora da UNIJUí (RS). 
no Brasil enquanto lugar de reprodução dos interesses das classes hegemônicas, não obstante o discurso de democratização e universalidade. Esse pressuposto levou-nos a analisar como as questões relativas à educação são discursivizadas, o que fizemos a partir da delimitação de um espaçotempo de análise tomado como referência, qual seja, o da $2^{\mathrm{a}}$ República (19301945), no sentido de lançar um olhar mais atento para os modos como a educação foi aí dita a partir do interior do discurso do Escolanovismo. A esse espaço discursivo contrapomos o do Movimento Libertário, cujas práticas e saberes foram disseminados no Brasil preponderantemente ao final da $1^{a}$ República. Esses dois lugares de discursivização serão aqui olhados enquanto Formações Discursivas (FD), no sentido que Foucault (2000) cunhou o referido termo para dar conta da idéia de uma filiação ideológica dos dizeres. Cumpre dizer, ainda, que os enunciados de uma e de outra FD serão considerados a partir dos pontos em que aparentemente dizem o mesmo, no entanto, estaremos reconstituindo os processos discursivos pelo viés da memória, para então chegarmos às diferenças que delimitam as fronteiras entre uma e outra FD. Para tanto, iniciaremos por uma discussão em torno do conceito de paráfrase discursiva, visto que os diferentes saberes que atravessam cada FD manifestam-se, nesse caso, via repetição, o que em princípio poderia remeter a uma leitura dos sentidos a partir da paráfrase lingüisticamente tomada e dos processos determinativos que explicitam as construções parafrásticas, e disso a necessidade de se delimitar a implicação do aspecto discursivo no conceito de paráfrase. E na busca de reconstituição dos lugares que derivaram as aparentes repetições trataremos também do conceito de memória discursiva, para então analisar, na perspectiva do antagonismo inerente às duas FDs, os modos como os objetos discursivos (enunciados) se linearizam e produzem sentido(s).

\section{O princípio da identidade no campo da filosofia}

A indagação sobre a natureza e as propriedades dos seres, no campo da Física, teve origem na filosofia grega do século VI a.C., assim como toda a ciência ocidental, em uma cultura onde, destaque-se, a ciência, a filosofia e a religião encontravam-se em declarada confluência. Salientese aqui a física, por centrar sua preocupação, à época, na tentativa da descoberta da essência das coisas, a physis. Os sábios de então, principalmente os adeptos da escola de Mileto, não diferenciavam o animado e o inanimado, como o fazemos hoje, todas as formas eram manifestações da physis, dotadas de vida e de espiritualidade.

Heráclito (540-470 a.C.) e Parmênides (530-460 a.C.), conforme atesta Moura Neves (1987), defendiam a idéia da existência de um desajuste 
entre o dizer e o agir, ou seja, a palavra que não corresponde à ação, em decorrência do lógos, transcendente a ela. Resultado disso é que "pensamento e realidade sensível se desvinculam; toma partida uma separação entre o lógos e a coisa" (p.30). Destaque-se ainda a concepção de Heráclito, para quem o mundo configurava-se em perpétua mudança, um eterno vira-ser. Para ele todas as transformações derivam da interação dinâmica e cíclica dos opostos, configurando-se, qualquer par de opostos, nessa perspectiva, como uma unidade. A essa unidade, que contém e transcende todas as forças opostas, denominava Logos.

Parmênides, por sua vez, inaugura uma tendência de pensamento que demarca a separação entre espírito e matéria, posto opor-se à unidade anteriormente descrita, a qual coincidia com o Princípio Divino. Parmênides postulou o Ser como sendo o seu princípio básico, descrito como único e invariável. No século V a.C., os filósofos gregos tentaram superar o contraste entre as duas visões, pressupondo que o Ser acha-se manifesto em determinadas substâncias invariáveis, cuja mistura e separação dá origem às mudanças do mundo. Essa tentativa de reconciliação deu lugar ao conceito do átomo, a menor unidade indivisível da matéria.

O nascimento da ciência moderna foi precedido e acompanhado por um desenvolvimento do pensamento filosófico que deu origem a uma formulação extrema do dualismo espírito/matéria, a qual veio à tona no século XVII, através de René Descartes. O cartesianismo daí derivado separa dois elementos implicados nas questões relativas ao conhecimento: 0 res cogitans (o relativo à mente) e a res extensa (relativo à matéria).

Essa formulação tem se revestido de importância capital para se entender os princípios do pensamento racionalista: a noção de que o caminho para a verdade implicita, necessariamente, a primazia da razão, expressa-se pela fórmula Cogito ergo. O Eu, extensão da causa primeira, Deus, postula-se, assim, como substância pensante, mesmo que pelo viés da dúvida. E o ato de pensar tem como matéria a extensio, o mundo material, entendidos a partir da razão humana ${ }^{1}$

Essa divisão teve consequiências que determinaram o modo de ser do homem ocidental até os dias de hoje, posto, a partir dela, configurar-se a limitação da identidade apenas à mente, e não à totalidade matéria/espírito. Os indivíduos vêem-se, dessa forma, compartimentados em sua própria morada, em que mente e corpo se "descolam", constituindo entidades à parte. E, o que vale destacar aqui, é que essa visão fragmentada é ainda mais ampliada quando se chega à sociedade, dividida em diferentes nações, raças e grupos políticos e religiosos.

${ }^{1}$ CAPRA, Fritjop. O Tao da Física. São Paulo, Cultrix, 1983. 
Pode-se falar, assim, na instauração de um outro paradoxo: o olhar fragmentado lançado sobre aquilo que se crê uno e imutável, enquanto que seria talvez bem mais coerente um olhar holístico lançado sobre o status das diferenças. Expliquemo-nos. Estamos aqui a tratar das construções parafrásticas em torno dos conceitos educacionais situados na Formação Discursiva Libertária, em contraponto com aqueles da Formação Discursiva Escolanovista. Se consideradas essas construções no plano estritamente lingüístico, serão entendidas como repetição, retomada de termos e expressões similares entre si. Ora, o desafio a que nos propomos aqui é, na perspectiva discursiva da paráfrase, depreender justamente os instantes singulares em que, aparentemente dizendo-se o mesmo, desliza-se para significados outros. Não obstante a unicidade última buscada por Heráclito, aderimos, com ele, ao princípio do vir-a-ser, do rio que, em sendo aparentemente o mesmo, inaugura sempre o irrepetível.

\section{A construção do conceito de paráfrase discursiva}

A noção de paráfrase aparece, no campo teórico da $\mathrm{AD}$, no texto de Pêcheux e Fuchs (1975), como articuladora dos sentidos, posto ser no interior das famílias parafrásticas que se constitui o que os autores denominaram de "matriz de sentido". Ora, famílias parafrásticas remetem a uma mesma filiação discursiva, razão por que daí deriva o sentido que pode ser entendido enquanto tal, se lido enquanto "efeito de", e não como "o sentido". A relação para com um determinado referente é, então, mediada pela filiação ideológica que aí se interpõe, por isso mesmo redefinido o sentido tantas vezes quantas forem as diferentes filiações. E tais estabilizações, é necessário dizer, constituir-se-ão exatamente pelo embate que encetarem com as demais filiações, ora aproximando-se, ora distanciando-se, fazendo assim, da polissemia, o necessário correlato da paráfrase. ${ }^{2}$

Afirmam os autores, em nota final do capítulo, que "não colocamos de início uma 'identidade de sentido' entre os membros da família parafrástica. Ao contrário, pressupomos que é nesta relação que sentido e identidade de sentido podem se definir" (p. 238). É, para eles, o processo de identificação do sujeito com os dizeres parafrásticos da Fd à qual encontra-se esse sujeito filiado que configurará o processo de assujeitamento, imbricando-se aí os dois esquecimentos, na medida em que o sujeito, ao mesmo tempo em que se acredita fonte e origem do sentido, acredita também que o conteúdo por ele enunciado só poderia ser aquele e não outro. Esse o duplo efeito de evidência. E se remetermos aqui aos campos da formação e da formulação, per-

${ }^{2} \mathrm{O}$ conceito de polissemia em relação ao de paráfrase foi trabalhado por Orlandi (1996). 
ceberemos que há também um nítido imbricamento do plano do interdiscurso, de onde procedem os enunciados, com o plano do intradiscurso, onde se linearizam. Extraídos da aparente desordem vertical, dispersos nas diferentes FDs, a partir da assunção do sujeito organizam-se no plano horizontal, aí constituindo sua pretensa estabilidade.

Pode-se dizer também que esse ponto de encontro entre o inter e o intradiscurso coincide com outra síntese: a do par individualidade/universalidade. A necessária ilusão discursiva a que está submetido o sujeito faz figurar a ilusão da apreensão de um sentido particular a uma determinada FD, como se fora universal.

Pêcheux e Fuchs (1975, p.238), em nota ao final do capítulo afirmam que as relações parafrásticas, no campo discursivo, não podem ser confundidas com a paráfrase lingüística, posto não se limitarem a relações simétricas entre termos. Não há ainda, nesse estágio da teoria da $\mathrm{AD}$ uma formulação apropriada para o conceito de heterogeneidade discursiva, a qual só viria a ser sistematizada mais tarde, por Courtine (1981). No entanto, percebe-se já a colocação da não univocidade dos sentidos, as portas para a abordagem dos enunciados em suas relações de tensão e confronto, mesmo que a partir de uma aparente homogeneidade.

Cabe aqui fazer uma análise do percurso da construção do conceito de paráfrase discursiva, posto ter sido o processo em si que configurou as diferentes nuances do termo, cada vez mais distante de paráfrase lingüística. Isso porque o dispositivo teórico da $\mathrm{AD}$ é em si um construto inacabado, renovado proporcionalmente às constatações teóricas que o campo da práxis faz emergir. Assim, remetemo-nos inicialmente para o texto da $\mathrm{AD} / 75$, o qual atualiza as proposições da $\mathrm{AAD} / 69$, refletindo, dentre outras coisas, sobre a impossibilidade de, diante da teoria do discurso, manter-se a idéia de análise semântica de um texto. (PÊCHEUX e FUCHS, 1975, p.169)

O projeto da AD/75 passa a conceber a existência de "famílias de paráfrases", ao invés de uma única família, até porque os discursos passam a ser considerados uns em relação aos outros, e não em seu suposto fechamento. Outro ponto de discussão é a natureza do significado nas famílias parafrásticas. Elas não correspondem, no caso, a proposições lógicas, posto situarem-se na dimensão do processo discursivo. Assim vistos, os enunciados desprendem-se do amarramento a uma análise puramente formal, porque convocam o exterior que lhes é condicionante. E é por isso também que, destacam Pêcheux e Fuchs, "os processos discursivos como foram aqui concebidos, não poderiam ter sua origem no sujeito. Contudo eles se realizam nesse mesmo sujeito" (p. 170). Esse é o cerne da contradição que explicita o caráter do assujeitamento do sujeito. 
Foucault já encetara essas discussões antes mesmo de Pêcheux. Em A Arqueologia do Saber, cuja primeira edição datou de 1969, ao discutir os objetos discursivos, o autor condiciona a formação deles a partir "de um conjunto de relações estabelecidas entre instâncias de emergência", de delimitação e de especificação" (FOUCAULT, 2000, p. 50). Assim, o conteúdo de uma determinada formação discursiva define-se em relação ao estabelecimento de "um conjunto semelhante". (ibid.)

Ao dizer que "os objetos de discurso se excluem, sem que tenham que se modificar a si próprios", Foucault aponta para as fronteiras que delimitam as diferentes Fds, noção formulada posteriormente por Courtine (1981), orientando-se pelo princípio da exclusão, pelo qual o que não pode ser dito em uma determinada Fd é extirpado de seus domínios. É assim que Foucault (2000, p.51) chega à conclusão de que "o objeto não preexiste a si mesmo, mas existe sob as condições positivas de um feixe complexo de relações".

Essa é a essência do processo discursivo, configurado nas ditas "relações entre as superfícies", as quais colocam-se enquanto "teias", vinculadas, emaranhadas entre si, e por isso, não estanque uma Fd da outra, como mais tarde viria a nos mostrar Courtine. E são essas relações que constituem os sentidos, porque as palavras, aprioristicamente tomadas, "estão tão deliberadamente ausentes quanto as próprias coisas" (ibid., p.55). Os discursos, portanto, não mais podem ser vistos como "conjuntos de signos (elementos significantes que remetem a conteúdos ou a representações), mas como práticas que formam sistematicamente os objetos de que falam". (ibid., p. 56)

Tal arquitetura configura-se em um campo de coexistência, posto que "um enunciado tem sempre margens povoadas de outros enunciados" (ibid., p.112). Por isso, o enunciado "não é simplesmente a utilização, por um sujeito falante, de um certo número de elementos e de regras lingüísticas" (ibid., p.113). Ele tem sim uma espessura material, contudo, essa materialidade está submissa, determinada pelas condições em que foi produzida. É em função de tais condições que os enunciados podem figurar-se estáveis, repetidos em sua identidade, mas, ao mesmo tempo, "também sob as identidades semânticas, gramaticais ou formais, as mais manifestas, definir um limiar a partir do qual não há mais equivalência, sendo preciso reconhecer o aparecimento de um novo enunciado" (ibid., p. 119).

Para Foucault são as condições históricas que definem as singularidades de um enunciado a cada reaparição sua. É de sua utilização em redes que emanam possíveis modificações e até apagamentos. As condições históricas situam-se em relação às instituições, aos processos econômicos e sociais, dentre outros, destacando o autor que tais relações "não 
estão presentes no objeto, não sendo elas que são desenvolvidas quando se faz sua análise". "Elas não definem a constituição interna do objeto, mas o que lhe permite aparecer" (2000, p. 51). Ratifica-se, assim, o processo discursivo como lugar que delineia a conformação do objeto, para além da superfície lingüística, mas não de um todo independente dela. É, pois, dessa forma que a formulação de uma determinada FD põe em evidência a necessária confluência entre a base lingüística e o processo discursivo.

Nessas redes os enunciados figuram como nós, caracterizados a partir de uma pluralidade de pontos que se constituem em torno da sequiência discursiva tomada como ponto de referência (sdr). Nessa rede, as sequiências discursivas (sd) são submissas a condições de produção ao mesmo tempo homogêneas e heterogêneas em relação à sdr, por isso, na condição similar à do nó, os enunciados estão necessariamente imbricados na pluralidade das condições que os determinam. Assim os elementos se repetem e variam, a partir de uma recorrência contraditória no interior do processo discursivo inerente a cada FD, desde que, no âmbito da linearização em que estão postos, simultaneamente convocam e excluem saberes antagônicos entre si.

Na perspectiva do domínio associado, no qual o enunciado está intrincado, há que se considerar o modo como ele se relaciona à rede de formulações. Tal enunciado situa-se, simultaneamente, em relação com as formulações, da ordem da horizontalidade, e com as formulações de outras sds, ancoradas na verticalidade do interdiscurso de uma determinada FD. Essa distinção é de importância capital, pois, ao postular a existência desses dois planos, não inteiramente desvinculados, Courtine acaba por configurar o enunciado como indissociável dos dois modos de existência do discurso enquanto objeto simultaneamente teórico e empírico.

Agora, pensando na concretização dos conceitos teóricos da AD, pode-se situar, como elemento constituinte do processo discursivo, o que Courtine (1981) denominou de parafrasagem discursiva, posto por ela ser possível recuperar/descrever a relação entre a língua e o seu exterior, relação acionável pela própria materialidade da língua.

Courtine recupera a construção teórica de Pêcheux (1975) pela qual “uma FD é um espaço de 'reformulação-paráfrase', e consiste em um sistema de reformulações, paráfrases e sinônimos" (COURTINE, 1981, p. 95), porém, desloca daí a noção de "construção de classes de equivalência distribucional que estabilizam a relação de substituição de $n$ segmentos discursivos em um contexto tanto estável como equivalente" (ibid.). Isso porque, acabamos de ver, tal estabilidade é relativa, e, por isso mesmo, não se pode dizer que haja equivalência plena. $\mathrm{O}$ autor destaca isso ao afirmar que "esta identidade semântica (repetição do idêntico) não se reduz, no 
entanto, em todos os casos, a uma pura e simples equivalência" (ibid., p.96). Em decorrência disso formula dois tipos diferenciados de substituição nos domínios semânticos: as substituições simétricas e as substituições orientadas. Na primeira há uma mera equivalência, do tipo da dicionarizada, seja no nível de morfemas, sintagmas ou das formulações. Já na segunda, dois termos dados em um determinado contexto não são equivalentes, embora possamos passar de um a outro e mesmo deduzir um do outro, "estabelecendo uma relação metonímica entre um e outro" (ibid.). Note-se, aqui há uma relação de pertença, em que o termo $a$ pode estar contido no termo $b$, e vice-versa, porém, não se confundem, posto cada um manter identidade própria.

Pêcheux (1975) abordou a paráfrase como "matriz de sentido", entendida enquanto construção de classes de equivalência distribucional, as quais possibilitam a relação de substituição dos vários segmentos discursivos num contexto estabelecido como equivalente. Essa substituição é caracterizada sob duas formas: a simétrica e a orientada. Para Courtine (1981) a paráfrase discursiva não se pauta sobre o princípio de identidade, porque está fundada na heterogeneidade dos processos discursivos, assim configurados face ao caráter contraditório inerente às FDs.

Grantham (2002), trabalhando a relação paráfrase/memória, remete a Orlandi (1999, p. 47) para afirmar que "é a constituição que determina a formulação, pois só podemos dizer (formular) se nos colocamos na perspectiva do dizível (interdiscurso, memória). Isso significa que todo dizer se encontra na confluência dos dois eixos, o da memória (constituição) e o da atualidade (formulação)". A FD, destaca a autora, comporta redes de formulação na medida em que constitui seu saber próprio, ou seja, a memória discursiva. É, pois, a memória que aciona o imaginário simulando seus efeitos na linearização do intradiscurso, onde, na aparente repetição, opera no discurso efeitos de mesmo elou diferente, ainda de acordo com Grantham.

A verdade refrata-se, pois, em possibilidades de verdade, o que substitui o lugar dos universais pelo das contingências. E a ordem da representação, por sua vez, constitui-se, em essência, pela ordem do simbólico, entendido esse naquilo que concerne ao campo das práticas coletivas que identificam os indivíduos entre os seus pares.

Resultado disso é que toma forma o caráter heterogêneo da linguagem, pois a possibilidade de interpretação a partir de diferentes posições assumidas fará intervir o discurso-outro. Assim, as paráfrases ressoam significativamente na verticalidade do discurso e concretizam-se na horizontalidade da cadeia, através de diferentes realizações. Dessa forma, apesar de inscrever-se na ordem do repetível, ao pôr em cena os conteúdos 
do já-dito, o sujeito pode promover efeitos de ruptura em seu dizer, constituindo os sentidos e sendo constituído por eles.

\section{FD Libertária e FD Escolanovista: os desencontros nos domínios da memória}

Elegemos, para fins de análise, duas formações discursivas, a) a do Movimento da Escola Nova, doravante referida como FDE, e cujas sequiências discursivas, tomadas enquanto referência, serão identificadas como Sdr e b) a formação discursiva da educação libertária, FDL, cujas sequiências discursivas $(\mathrm{Sd})$ serão contrapostas às da FDE. Essa última diz respeito ao conjunto de saberes inerentes às práticas discursivas de indivíduos engajados na proposição de um ensino que se configurasse enquanto expressão de um projeto maior, tido como não disciplinarização, ${ }^{3} \mathrm{e}$, acima de tudo, não fragmentação, face à crença na formação do indivíduo de forma plena, abrangendo as diferentes facetas da razão. Esse conjunto de saberes tem seu berço na Europa, mais especificamente no movimento Anarquista, cuja doutrina constitui-se, segundo Faure (1981), como "um grupo de princípios gerais, conceitos fundamentais e aplicações práticas, segundo os quais foi estabelecido um consenso entre indivíduos cujo pensamento é contrário à Autoridade, e que lutam, coletiva e isoladamente, contra toda disciplina e repressão, sejam elas políticas, econômicas, intelectuais ou morais". Desse modo, a memória discursiva que funda a FDL não se limita ao aspecto educacional, mas coloca-o no bojo das discussões em torno do político e do econômico, no sentido de que a superação das condições subumanas de trabalho a que a classe proletária estava submetida passava, necessariamente, pelo trabalho a partir da base intelectual. Cumpre destacar que o contingente de trabalhadores era composto, em grande parte, por imigrantes e filhos de imigrantes, o que propiciou a discursivização das questões educacionais no conjunto de saberes filiados à causa libertária, em voga na Europa e assumida por muitos dos trabalhadores que para cá emigraram.

Já a Formação Discursiva Escolanovista constitui-se a partir do conjunto de saberes do movimento de renovação educacional surgido na Europa e na América entre o fim dos Oitocentos e o início dos Novecentos. Tal movimento é fruto do questionamento do modelo educacional da República Velha, que, de certa forma, reproduzia o modelo imperial, voltado exclusivamente para as elites, face à crise sócio-econômica desencadeada

${ }^{3}$ A Fd libertária condena tanto a disciplinarização dos conteúdos quanto o regramento, a coerção do comportamento humano. 
pela consciência da divisão de classes, que começava a assumir contornos mais bem definidos.

O Escolanovismo situou-se sobre duas dicotomias, conforme Manacorda (1997, p. 304-5): "a presença do trabalho no processo da instrução técnico-profissional (...) e a descoberta da psicologia infantil com suas experiências 'ativas'". Analisa o autor que o conceito de trabalho atravessa o campo da educação por duas vias, ora antagônicas, ora aliadas entre si; primeiramente, o desenvolvimento objetivo das capacidades produtivas sociais, oriundas da revolução industrial, caminho esse que equipara o ser humano às máquinas. ${ }^{4}$ Já o segundo enfatiza a espontaneidade da criança, sua livre atividade, desenvolvimento afetivo e socialização, razão por que o jogo e o trabalho são tidos como elementos educativos, devendo estar sempre presentes na escola. Assim, embora por vias antagônicas, acabam por encontrar-se no denominador comum "trabalho", enquanto elemento formativo, pois visam o mesmo objetivo, "o homem capaz de produzir ativamente" (ibid., p.305). Numa primeira leitura parece haver uma similitude com as escolas racionalistas, postos os princípios escolanovistas de autogoverno e cooperação.

Às diferentes condições de formação de cada FD corresponde uma diferente configuração dos saberes que lhes são inerentes. Assim, as escolas racionalistas fundam-se com o intuito de desenvolvimento do indivíduo em todas as facetas de sua razão, uma vez despojado de possíveis amarras a crenças e atitudes de subservilismo. A educação é vista nesse contexto como "espaço privilegiado para a formação da consciência revolucionária" (KASSICK, 1996, p.84), e por essa mesma razão os pressupostos pedagógicos libertários inscrevem-se na mesma configuração política dos imigrantes operários que para cá os trouxeram, aliados às "atividades de militância, imprensa, panfletagens, greves, enfim, todo um conjunto de ações diretas articuladas que forneciam, ao mesmo tempo, aos trabalhadores, os elementos para lutarem por melhores condições de vida e uma cultura de base superior aos demais trabalhadores (...)". (ibid.)

O Movimento da Pedagogia da Escola Nova surgiu em meio à efervescência política do Brasil da década de 30, quando múltiplos Projetos de Reformas Educacionais foram apresentados, todos resultantes da crença de que as mudanças no campo da educação poderiam ser feitas via regulamentação legal. Ao contrário do movimento libertário, cujos militantes filiavam-se a uma orientação política definida, o escolanovismo colocava-se sob um forte ecletismo, inscrevendo o liberalismo em suas práticas. Dentre os expoentes desse movimento destacamos Francisco Cam-

${ }^{4}$ Os grifos são nossos.

132 
pos, Fernando de Azevedo, Lourenço Filho e Anísio Teixeira.

Duas forças aparentemente antagônicas delineavam os pressupostos do escolanovismo: uma que defendia um ensino democrático, emancipatório e laico, e outra que preconizava um ensino elitista, conservador e de caráter religioso. Não obstante essas diferenças, o fim último do projeto escolanovista era atender aos objetivos do Estado na educação, com formação específica para cada estrato social, embora se discursivizasse sobre a oferta universal do ensino. Desse modo, o referido movimento conformava-se ao intuito de desenvolvimento econômico e produtivo da nação.

A essa postura opunham-se os saberes libertários, cujo projeto educacional, como já dissemos, visava à emancipação político-social do indivíduo. Em razão disso as atividades de ensino encontravam-se mescladas a outras de cunho cultural, tais como o teatro, a música e as bibliotecas livres, atividades essas colocadas à disposição dos trabalhadores operários, com vistas à sua formação intelectual. A isso se somavam "seções de leituras comentadas nos locais de trabalho, à hora do almoço; os debates ideológicos, em conferências e palestras; controvérsias nos círculos de estudos (...), com o estímulo permanente ao estudo e à superação do obscurantismo". (RODRIGUES, 1992, p. 48-9)

No Brasil tivemos algumas experiências significativas em termos de criação de escolas racionalistas, as quais seguiam os princípios libertários, a maior parte delas seguidoras do modelo da Escola Moderna, de Barcelona, fundada por Francisco Ferrer y Guardia, em 1901. Dentre as experiências em solo brasileiro a Escola Eliseu Reclus, fundada no Rio Grande do Sul; a Escola Sociedade Internacional, em Santos, no ano de 1907; a Escola Livre, em Campinas; a Escola Moderna $\mathrm{n}^{\circ} 1$ e a n ${ }^{\circ}$ 2, de São Paulo, fundadas em 1909, e ainda a Universidade Popular, fundada no Rio de janeiro em 1904 (RODRIGUES, 1992). As práticas preconizadas por essas escolas assentavam-se nos princípios racionalistas do movimento libertário, pelo que defendiam, para além do mero aprender a ler e escrever, o aprendizado da "verdade histórica, científica e social". (p. 54)

Assim, a partir da fronteirização dessas duas instâncias de discurso as designações empregadas para falar da educação assumem contornos bastante diferenciados, consoante a afirmação de Pêcheux (1988, p.160) de que "as palavras, expressões e proposições, etc., mudam de sentido segundo as posições sustentadas por aqueles que as empregam, o que quer dizer que elas adquirem seu sentido (...) em referência às formações ideológicas nas quais essas posições se inscrevem". Desse modo, designações como ensino integral e experiência, por exemplo, em alguns casos também ratificadas por construções determinativas, aparentemente parafrásticas nas duas FDs, revelam-se profundamente diferentes, posto 
que relacionam-se a diferentes condições históricas de produção, por isso evocando diferentes domínios de saberes e, por conseguinte, passam a produzir distintos sentidos.

Os objetos discursivos: as condições de formação e os efeitos de sentido via linearização

Trazemos, a seguir, os enunciados das duas FDs em jogo, identificados os da FD Escolanovista como Sdr e os da FD Libertária como Sd. Eles estão aqui postos em contraponto imediato, para que melhor visualizem as confluências e desencontros, o que passamos a seguir a analisar:

Sdr1: A educação nova, alargando a sua finalidade para além dos limites das classes, assume, com uma feição mais humana, sua verdadeira função social, preparando-se para formar a "hierarquia democrática" pela hierarquia das capacidades", recrutadas em todos os grupos sociais, a que se abrem as mesmas oportunidades de educação. Ela tem por objeto, organizar e desenvolver os meios de ação durável com o fim de "dirigir o desenvolvimento natural e integral do ser humano em cada uma das etapas de seu crescimento (...). (GHIRALDELLI, 1990, p.59)

Sd1: Como proposta educativa o ensino deverá e poderá ser verdadeiramente:

a) integral, isto é, favorecer ao desenvolvimento harmonioso de todo o indivíduo e fornecer um conjunto completo, coerente, sintético e paralelamente progressivo em todos os domínios do conhecimento intelectual, físico, manual e profissional, sendo as crianças exercitadas nesse sentido desde os primeiros anos (...). (KASSICK, 1996, p.89)

O primeiro enunciado, pertencente ao Manifesto dos Pioneiros da Educação Nova (1932), diz, na superfície linguiística, sobre a igualdade na oferta de educação para todas as classes, indistintamente, ao afirmar que a educação nova tem sua finalidade alargada para além dos limites das classes. No entanto, ao recuperarem-se as condições históricas em que tal enunciado foi formulado, constata-se um nítido projeto de manutenção da estratificação social também na educação, uma vez que à época não eram propiciadas as condições efetivas para que, por exemplo, crianças de apenas sete anos de idade pudessem abandonar as fábricas e dedicar-se aos estudos. A não vontade de oferta plena e igualitária de ensino é justificada pelo critério "hierarquia das capacidades", quesito esse que justifica a "hierarquia democrática". Assim, a construção determinativa "recrutadas em todos os grupos sociais, a que se abrem as mesmas oportunidades de educação", referindo-se às capacidades, gera um efeito de sentido de auto- 
anulação, ao mascarar as diferenças de condições que são específicas de cada estrato social, e que demandariam, por isso mesmo, diferença de tratamento, e não uma suposta homogeneização que encobre as referidas diferenças. Ora, numa sociedade com disparidade social acentuada, figura por demais contraditório estabelecer as capacidades do indivíduo como condição para sua inserção social, uma vez que nem sempre lhe são oferecidas as condições necessárias para o desenvolvimento de suas capacidades. De fato, tal proposição convoca um domínio de memória inerente à FDE e que emana, em primeira instância, do pensamento do aparelho estatal, o de que as classes mais abastadas economicamente deveriam ser preparadas para os postos de liderança e para as profissões liberais, enquanto às classes menos favorecidas restava a ocupação dos postos de trabalho de menor prestígio, por isso acreditando-se que a esses indivíduos era dispensável a formação intelectual.

A esse saber opõe-se o enunciado proposto na Sd1, formulado no contexto da fundação da Escola Moderna, de Barcelona, e reproduzido no Brasil por ocasião do processo de implantação das escolas libertárias que aqui tivemos. Nesse enunciado, o da $\mathrm{Sd} 1$, a proposta de formação integral e progressiva do indivíduo sobrepõe-se à segmentação social, implicando que também o sujeito operário deva ter formação intelectual, e mais do que isso, coerente com os domínios de memória da FDL, fica posto que é exatamente a emancipação pela base intelectual que vai possibilitar ao indivíduo a superação de sua condição de subserviência e exploração. O ensino integral, condição para a emancipação político-econômica dos sujeitos é explicitado pela construção lingüística determinativa que o define como conjunto completo, coerente, sintético e paralelamente progressivo em todos os domínios do conhecimento intelectual, físico, manual e profissional. Tal construção remete ao domínio de memória específico dos saberes libertários, nos quais só poderia ser concebido um ensino que abordasse a educação em suas múltiplas facetas, como o demonstra a proposição de Ferrer por ocasião da fundação da Liga Internacional para a Educação Racional da Infância em seu artigo $2^{\circ}$ :

A instrução é apenas uma parte dessa educação. A educação deve compreender, também, junto com a formação da inteligência, o desenvolvimento do caráter, o cultivo da vontade, a preparação de um ser moral e físico bem equilibrado, cujas faculdades se associem harmoniosamente e sejam levadas à sua máxima potência. (RODRIGUES, 1996 , p. 90)

Desse modo, algumas designações fazem-se presentes nos enunciados das duas FDs, tal como desenvolvimento integral, prova de que, enquanto palavra, habitam o desnivelamento vertical do interdiscurso, as- 
sumindo significação estável apenas na linearização intradiscursiva de cada FD, porque aí evocam memórias discursivas bastante adversas.

Sdr2: A escola, vista desse novo ângulo, que nos dá o conceito funcional da educação, deve oferecer à criança um meio vivo e natural, "favorável ao intercâmbio de reações e experiências', em que ela, vivendo a sua vida própria, generosa e bela de criança, seja levada 'ao trabalho e ação por meios naturais que a vida suscita quando o trabalho e a ação convém aos seus interesses e às suas necessidades". (GHIRALDELLI, 1990, p. 66)

Sd2: "A experiência, a observação direta, recreação instrutiva serão muito mais favorecidas pelo professor que compreende a sua missão do que as longas e fatigantes preleções e as recitações fastidiosas e sem sentido". (RODRIGUES, 1992, p 23)

Experiência e contato com situações concretas de aprendizagem são a tônica das duas Fds. Trata-se do mesmo multifacetado em saberes diferenciados. Na Sd da FDL, a remissão ao campo da memória discursiva dos saberes anarquistas que preconizavam o fazer como sendo anterior ao saber e constitutivo dele. Kropotkin (1989), ao tratar da concepção do trabalho operário, defendendo a primazia da capacidade inventiva, na história da ciência, capacidade essa que é somente seguida da teorização, formula dois enunciados considerados matrizes de sentido para essa posição-sujeito em que o fazer leva ao inventar e refletir sobre o fato de que

a) em noventa e nove por cento dos casos, a invenção mecânica vem antes do descobrimento da lei científica (p.64);

b) é evidente que cada invento se aproveita dos conhecimentos acumulados previamente e das formas de sua manifestação. Mas em geral ele se sobrepõe ao que se sabe, dá um salto no desconhecido e, deste modo, abre uma nova série de fatos que a pesquisa oferece. (p.65)

Muito diversa é a relação proposta na FDE, em que o fazer leva ao fazer, sustentado pela seguinte proposição: "de acordo com suas necessidades". Ora, que necessidade produtiva tem a criança de "fazer" em sua vida "bela"? Aí está suscitada a visão romântica da infância, na qual, exatamente por não haver demandas utilitárias, interesses de outras esferas podem ser importados, a saber, os da ótica capitalista, na qual convém "treinar" o futuro operário. Assim, ao mesmo tempo em que se propõe enquanto movimento renovador, endossado na construção determinativa de escola "vista sob um novo ângulo", o que o projeto escolanovista faz é ratificar os projetos educacionais vigentes no final da $1^{a}$ República, e aos quais tão fortemente o movimento libertário resistiu.

Sdr3: A escola nova, que tem de obedecer a esta lei, deve ser reorganizada de maneira que o trabalho seja seu elemento formador, favorecendo a expansão das energias criadoras do educando, procurando estimular-lhes o 
próprio esforço como o elemento mais eficiente em sua educação e preparando-o (...), para fazê-lo penetrar na corrente do progresso material e espiritual da sociedade de que proveio e em que vai viver e lutar. (GHIRALDELLI, 1990, p. 67)

Sd3: Toda educação que não prepara a criança para esse duplo papel (trabalho-educação), que não tende a fazer dela ao mesmo tempo um trabalhador, no mais largo sentido da palavra, um ser inteligente e um ser ativo, é uma educação incompleta e estéril (FolHA Do Povo. São Paulo, n. 24)

A Sdr3, da FDE, ratifica o lugar conferido ao trabalho em seus saberes, conforme já discutimos na análise anterior, assentando a necessidade da preparação para o trabalho em uma lei para a qual "a vida da sociedade, individual e coletiva se manifesta pela sua produção material" ${ }^{5}$. Desse modo, o trabalho é o fim primeiro e último da educação, sobrepondo-se a ela, razão pela qual a educação se coloca a serviço do intento de formação do trabalhador, mais especificamente, da mão-de-obra que interessa ao estado na época. Tanto o é, que a promessa de entrada no progresso material é situada como horizonte de perspectiva da função educativa. No entanto, as práticas da $2^{\mathrm{a}}$ República desconfirmam a promessa utópica de criação igualitária de condições de acesso ao progresso material para todos os indivíduos. Impossibilitados, em sua maioria, de aceder à escola, aos que o conseguiam, dentre a classe proletária, oferecia-se o mínimo indispensável para a continuidade da execução das tarefas mais precárias, as quais, acreditava-se, nessa perspectiva, dispensavam a reflexão teórica, e por isso a fragmentação trabalho manual/trabalho intelectual. Esse domínio de saber, inerente à FDE, ratificava o intento de manutenção da estratificação social, corroborada, inclusive, pela proposição da inserção do indivíduo na corrente do progresso material, não com vistas à sua emancipação econômica, mas exatamente à manutenção de sua condição, posta a especificação da sociedade de que proveio e em que vai viver e lutar.

A idéia do trabalho enquanto elemento inerente à formação dos indivíduos não é estranha à FDL, no entanto, assenta-se sob leis completamente diversas. Diversamente aos saberes do escolanovismo, a proposição do trabalho interior da FDL filia-se à também idéia de preparação do indivíduo, porém, não se sobrepõe à tarefa educativa, mas delineia-se como um dos aspectos de formação dele, e mais do que isso, pressupõe não apenas o mero fazer, mas principalmente o desenvolvimento da inteligência, ou seja, a não fragmentação trabalho/reflexão, teoria/prática, ao ponto de qualificar a educação como não devendo se prestar a um papel "estéril" se assim não o fizesse.

${ }^{5} \mathrm{O}$ referido princípio consta no próprio Manifesto dos Pioneiros da Educação Nova. 
Desse modo, percebe-se que a designação trabalho, não obstante se fazer presente nas duas FDs, articula-se por diferentes determinações discursivas. Lingüisticamente este posta a discussão em torno da relação escola/trabalho pelas construções relativas, tanto na FDE quanto na FDL. No entanto, na primeira essa construção diz respeito a um saber préconstruído que se situa em torno da reprodução da conformação social, enquanto que na FDL diz exatamente sobre a mudança da estratificação estabelecida e pela qual ao operariado cabe servir como mão-de-obra, sem se vislumbrar a possibilidade de emancipação dessa condição.

\section{CONSIDERAÇÕES FINAIS}

As sequiências discursivas aqui abordadas não estabelecem, em sua totalidade, relações parafrásticas diretas, como é o caso da recorrência do termo trabalho, a exemplo da Sdr3 e Sd3. O que há, também, são aproximações lexicais que simulam um campo semântico, e nas quais os sentidos muitas vezes são aproximados, por inferências do tipo contato direto, que pressupõe experiência, como é o caso da $\mathrm{Sd} 2$ e da $\mathrm{Sdr} 2$. Ambas as Formações Discursivas parecem engajadas nos mesmos princípios, pela LÍNGUA - MEIO DE ACESSO AOS QUADROS DA MEMÓRIA.

Similaridade das designações, como é o caso, também, dos termos experiência e formação integral, elementos comuns às duas FDs. Porém aí mesmo é operado o deslizamento, pelas filiações de cada uma delas, que, antagônicas, configuram-se como pertencendo a diferentes ordens, remetendo a sentidos também antagônicos. Assim, os sujeitos que dizem, nessas diferentes práticas, bem como os saberes que eles aí evocam, de diferentes ordens, configuram-se na dessemelhança com o Zeitgeist, "o espírito do tempo", assim definido por Pêcheux (1988, p.144). Isso porque o tempo histórico não é linearmente tomado, mas sim correlato à dispersão do sujeito que nele se delineia.

As construções parafrásticas são tomadas da rede interdiscursiva, e, na linearização do intradiscurso, assumem identidade segundo a filiação em que se inserem, sendo via reconstituição do trajeto da memória discursiva que se deixam entrever os processos que permitiram agregar sentidos diferenciados para cada Formação Discursiva. E, vale destacar ainda, que não se trata da memória cognitiva, mas da memória coletiva que ressoa nos dizeres, ora repetida, ora transmutada. E a língua, enquanto materialidade, constitui-se enquanto meio de acesso aos diferentes quadros da memória, razão pela qual sua aparente estabilidade há que ser desestratificada, acedendo-se ao plano do interdiscurso, de onde os enunciados derivaram, de diferentes Formações Discursivas, para então assentarem-se na aparente 
estagnação da cadeia sintagmática. É desse modo, pois que se pode dizer que, as repetições apontam para a não retomada e não estabilização dos sentidos, mas constituem-se deriva pura, de modo que se associam a distintos projetos político-educacionais.

É sabido que o Movimento da Escola Nova estabeleceu-se no Brasil no contexto do Estado Novo, quando

ao conjunto de ações administrativas somam-se práticas políticas de sedução da classe proletária, as quais se concretizam através de discursos de aliança que visam à inserção do operariado no contexto educacional brasileiro e que convertem os deveres do Estado em benefícios concedidos ao operariado através de ações tais como a promoção de instrução gratuita, a multiplicação de escolas noturnas (...) (ZANDWAIS, 2002)

Assim, o que o discurso da FD Escolanovista tenta fazer, é sobrepor-se aos saberes da FD Libertária, porque, dizendo sobre a oferta de ensino integral, experiencial e voltado à formação para o trabalho, gera o efeito de sentido de que está a atender as demandas da classe operária, e mais, que tudo isso seria proporcionado gratuita e indistintamente, pressupondo a oferta universal de ensino. Com isso apagam-se não somente as diferenças de classe e de condições de acesso, como também o ideal revolucionário do movimento das escolas libertárias. Desde que se tem uma educação oferecida pelo aparelho estatal, dispensando a necessidade de luta pela conquista do direito à formação plena dos indivíduos. Porém, importa ressaltar, o preço dessa educação dita gratuita é a subserviência aos interesses do Estado e desistência da bandeira de lutas da classe proletária, denotadamente as lutas encetadas pelos sujeitos imigrantes e filhos de imigrantes que se encontravam em solo brasileiro, servindo como força de trabalho, porém alijados da possibilidade de acesso ao ensino, pelo que viabilizaram formas próprias e alternativas de fazê-lo, como foi visto no decorrer desse estudo.

Importa dizer, ainda, que a literatura que aborda o panorama da história da educação no Brasil tem, em grande medida, silenciado sobre as práticas libertárias, colocando, no plano da discussão em torno do intuito de emancipação política exatamente os saberes do escolanovismo, o qual, ao se manifestar enquanto discurso de aliança para com os interesses do Estado, produz o efeito de sentido de que nunca houve resistência nesse país, reproduzindo a falsa idéia de um povo e uma nação pacíficos, cujos interesses são de pronto sempre atendidos pelo poder instituído. Porém, é preciso dizer, se as escolas libertárias foram silenciadas à força, pelo fechamento compulsório de que foram alvo no início do século XX, algumas sendo até incendiadas, isso não implica, necessariamente, que os saberes 
nelas veiculados o tenham sido também, razão pela qual aqui estamos a falar sobre eles, tingindo de cores específicas suas diferenças, delimitando suas fronteiras, desmistificando as pretensas semelhanças com tudo aquilo que foi exatamente excluído de seu interior.

\section{BIBLIOGRAFIA}

COURTINE, Jean-Jacques. Analyse du discours politique. Paris, Larousse, Langages, n.62, juin 1981.

FAURE, Sébastien. Anarquia - Anarquista. In.: WOODCOCK, George. Os grandes escritos anarquistas. São Paulo, L \& PM , 1981.

FOUCAULT, Michel. A arqueologia do saber. Rio de Janeiro, Forense Universitária, 2000.

GHIRALDELLI Junior, Paulo. História da educação. São Paulo, Cortez, 1990.

GRANTHAM, Marilei R. Da releitura à reescritura; um estudo da leitura pelo viés da pontuação. Porto Alegre, Programa de Pós-graduação em Letras da UFRGS, 2002. (Tese de Doutorado).

HAROCHE, Claudine. Fazer dizer, querer dizer. São Paulo, Hucitec, 1982.

KASSICK, Clóvis Nicanor. O movimento das escolas alternativas no Brasil; o ressurgir da educação libertária? In: Educação libertária: textos de um seminário. Florianópolis, Movimento Centro e Cultura de Autoformação, 1996.

KROPOTKIN, Pedro. Trabalho cerebral e braçal. In.: MORIYÓN, F.G. (org.). Educação libertária. Porto Alegre, Artes Médicas, 1989.

LUCKESI, Cipriano. Filosofia da educação. São Paulo, Cortez, 1994.

MANACORDA, Mario Alighiero. História da educação; da Antigüidade aos nossos dias. São Paulo, Cortez, 1997.

MOURA NEVES, Maria Helena de. A Vertente Grega da Gramática Tradicional. São Paulo, Hucitec, Ed. da Universidade de Brasília, 1987.

ORLANDI, E. Puccinelli. O sentido dominante: a literalidade como produto da história. In.: A linguagem e seu funcionamento: as formas do discurso. Campinas, SP, Pontes, 1996.

PÊCHEUX, Michel. Semântica e discurso: uma crítica à afirmação do óbvio. Campinas, Ed. da UNICAMP, 1988. 
Análise automática do discurso (AAD-69). In: GADET, F. \& HAK, T. (org.). Por uma análise automática do discurso; uma introdução à obra de Michel Pêcheux. Campinas, Ed. da Unicamp, 1990.

PÊCHEUX, M. e FUCHS, C. A propósito da análise automática do discurso: atualização e perspectivas. (1975). In: GADET \& HAK (org). Por uma análise automática do discurso: uma introdução à obra de Michel Pêcheux. Campinas, Ed. da Unicamp, 1990.

PROUDHON, Pierre-Joseph. O nascimento da anarquia: a morte da propriedade. In.: WOODCOCK, George. Os grandes escritos anarquistas. São Paulo, L \& PM ,1981.

RODRIGUES, Edgar. O anarquismo na escola, no teatro, na poesia. Rio de Janeiro, Achiamé, 1992.

ZANDWAIS, Ana. Saberes sobre ensino-aprendizagem de língua portuguesa no estado novo: dos pressupostos do Plano Nacional de Educação às práticas de correção de textos no Colégio D. Pedro II. Trabalho apresentado no XVII Encontro Nacional da Anpoll, Gramado, 2002. 